American Journal of Pharmaceutical Education 2019; 83 (6) Article 6825.

\title{
RESEARCH
}

\section{An Individual Development Plan for Pharmacy Students for Career Planning and Tracking Accreditation Standards}

\author{
Deanna Gee, PharmD, Margaret Schulte, PharmD, Rae R. Matsumoto, PhD \\ Touro University California College of Pharmacy, Vallejo, California \\ Submitted September 26, 2017; accepted January 11, 2018; published August 2019.
}

\begin{abstract}
Objective. To create and implement individual development plans (IDPs) to assist pharmacy students in career planning and tracking their achievement of ACPE Standards 2016, Standard 4, for Personal and Professional Development.

Methods. First-year Doctor of Pharmacy students completed IDPs, which were subsequently reviewed to ensure they addressed components of the ACPE Standard 4 key elements: self-awareness, leadership, innovation and entrepreneurship, and professionalism. Faculty advisors were surveyed regarding the utility of IDPs. Descriptive statistics were used to evaluate the results.

Results. Self-awareness (100\%) and professionalism (100\%) were the key elements most commonly documented by pharmacy students, followed by leadership (51\%), and innovation and entrepreneurship (22\%). Faculty advisors reported IDPs as beneficial for stimulating individualized career planning and tracking achievement of ACPE Standard 4.

Conclusion. Most students enter pharmacy school recognizing the importance of self-awareness and professionalism, but require additional training to instill leadership and innovation/entrepreneurship skills. Individual development plans can be implemented in pharmacy education as a cornerstone of personal and professional development planning, as well as a means of tracking a school's progress toward meeting accreditation standards.
\end{abstract}

Keywords: individual development plan, ACPE Standard 4, personal and professional development, career planning, self-evaluation

\section{INTRODUCTION}

As the practice of pharmacy rapidly evolves with the expansion of more clinical roles for pharmacists, defining career goals and making career decisions is an even greater challenge for pharmacy students. The individual development plan (IDP) is a structured mechanism originally used in graduate science education to help $\mathrm{PhD}$ candidates and postdoctoral researchers self-evaluate their skills, define career goals, and develop individualized implementation plans that would allow them to achieve their stated goals. ${ }^{1-7}$ The value of IDPs is widely recognized in biomedical graduate education, and since 2014, the National Institutes of Health (NIH) has strongly encouraged graduate programs to use this tool in the training of graduate students and postdoctoral researchers. ${ }^{8}$ The NIH specifically states that the implementation of IDPs assists graduate students and postdoctoral researchers in achieving

Corresponding Author: Rae R. Matsumoto, Touro University California College of Pharmacy, 1310 Club Dr., Vallejo, CA 94592. Tel: 707-638-5926. Fax: 707-638-5959. E-mail: rae.matsumoto@tu.edu their career goals. ${ }^{4}$ Although IDPs are used by graduate students and postdoctoral researchers in the pharmaceutical sciences, currently the utility of implementing IDPs has not been assessed in pharmacy education.

The 2016 Accreditation Council for Pharmacy Education (ACPE) standards call for personal and professional development of pharmacy graduates. This is outlined in ACPE 2016 Standard 4 Personal and Professional Development. ${ }^{9,10}$ Key elements of Standard 4 emphasize self-awareness, leadership, innovation and entrepreneurship, and professionalism. ${ }^{9}$ These four key elements are also embedded in Domain 4, Personal and Professional Development, of the 2013 Center for the Advancement of Pharmacy Education (CAPE) Educational Outcomes. ${ }^{11}$ Multiple mechanisms have been developed by pharmacy schools to address the key elements of personal and professional development, including specialized coursework, targeted curricular elements, and cocurricular activities. ${ }^{12-14}$ Additionally, validated assessment tools to measure these key elements are still being developed, particularly for pharmacy students. Nevertheless, ensuring the application of these elements 


\section{American Journal of Pharmaceutical Education 2019; 83 (6) Article 6825.}

of personal and professional development is essential, especially as opportunities expand in the pharmacy profession and students express concerns about being able to navigate their career choices and prepare themselves for these varied roles.

To address this challenge, an IDP template with a pharmacy education emphasis was developed to aid Doctor of Pharmacy (PharmD) students in their personal and professional growth as they plan for their future in a changing environment. The primary objective of this study was to assess whether the IDP could be implemented into pharmacy education as a cornerstone of the personal and professional development plan for students and serve as a component in tracking key elements of ACPE Standards 2016, Standard 4. While the IDP is designed to ultimately serve as a longitudinal tool, this paper focuses on data and outcomes from the first-time use of the IDP in a new class of PharmD students at a private pharmacy school.

\section{METHODS}

An IDP template was created (Appendix 1) to guide pharmacy students in career planning and serve as a living document that could be updated on a regular basis as career goals developed, competencies improved, and new needs were identified. The IDP had three sections: professional goals, self-evaluation, and action plan. In the professional goals section, students clarified short-, medium-, and long-term (ie, one-, five-, and 10-year) professional goals and identified characteristics needed to achieve their stated goals. In the self-evaluation section, pharmacy students identified strengths and weaknesses in specific skills categories.

To create the self-evaluation section, an IDP template taken from graduate education was modified to focus on assessing skills valued in the practice of pharmacy. A literature search was done to identify common characteristics valued by pharmacy employers and residency or postdoctoral programs. ${ }^{15-18}$ Skill categories were constructed from this information, then vetted and refined based on feedback from a select group of clinical pharmacy faculty members from private and public universities. These skill categories and characteristics were listed in the self-evaluation section for pharmacy students to identify as strengths or weaknesses.

We intended that each student would keep an updated inventory of their perceived strengths and weaknesses throughout the Doctor of Pharmacy (PharmD) program and beyond, and would have or develop strengths that aligned with the characteristics required to achieve their desired career goals. In the last section, the action plan, each student developed a customized roadmap for achieving their stated career goals and a plan for improving necessary competencies.

All first-year PharmD students were required to attend an IDP informational session as part of their orientation. During the informational session, study investigators explained the purpose of the IDP and provided instructions to students on the use of the tool, then students were given the opportunity to begin completing the form and ask questions. Each student was required to complete an IDP and upload the document to their $E^{*}$ Value (MedHub, Minneapolis, MN) portfolio by September 30, 2016, about two months after beginning the PharmD program. Students were required to meet with their academic advisors before the end of the first semester, and discussion of the IDP was an expected part of the meeting. Maintenance of the E*Value portfolio, including the completed IDP, was a graded component of the semester coursework.

In preparation for implementation of the IDPs, a faculty development session was conducted prior to the beginning of the school year to introduce the format and structure of the tool. In addition, a list of existing resources in the PharmD program to support the development of self-awareness, leadership, innovation and entrepreneurship, and professionalism were provided to the faculty members. Ten faculty members were subsequently assigned to serve as academic advisors for the incoming class. After the end of the semester, a survey (Appendix 2) was distributed to the 10 academic faculty advisors to assess their perceptions of the utility of the IDP for stimulating personal and professional development in PharmD students. The survey responses of the academic advisors to the eight yes-or-no questions were summarized as percentages.

Descriptive statistics were used to evaluate the data. Each IDP form was de-identified by a staff member who was not a study investigator. Printed, de-identified copies of the IDPs were organized in binders and stored under double locks in faculty offices. The IDP data were also stored in password-protected Excel files that were accessible only by the study investigators. Three study investigators evaluated the ability of the IDPs to address the ACPE accreditation standard for personal and professional development by independently scoring each IDP using a standardized rating scale $(0=$ absent/not reported on the IDP, $1=$ present/reported on the IDP) for each of the required key elements (self-awareness, leadership, innovation and entrepreneurship, and professionalism) using operational definitions provided in the 2016 ACPE Accreditation Standards and the Guidance for Standard 4. ${ }^{9,10}$ To further document the nature of the reported items, the investigators also assessed whether students 


\section{American Journal of Pharmaceutical Education 2019; 83 (6) Article 6825.}

had reported the key elements as attained or needing development using a standardized rating scale $(0=$ absent $/$ not reported, $1=$ present/reported). It was possible for a key element to be scored as both attained and needing development. In the professionalism category, for example, a student may have indicated that they were always on time (score of 1 for reporting that it had been attained), but needed to work on oral communication skills (score of 1 for reporting that it needed development). The data were coded for each category based on the majority consensus rating of the study investigators (ie, the rating assigned by two out of three or three out of three study investigators). This descriptive study was determined to be exempt by the Investigational Review Board at Touro University California.

\section{RESULTS}

Of the 105 first-year pharmacy students who attended the IDP orientation session, one student who withdrew from the program was excluded from the study. Therefore, the data from 104 full-time, first-year pharmacy students are reported. Demographic characteristics of the sample are summarized in Table 1.

The percentages of students that indicated attainment of or needing development for each key element are presented in Figure 1. There was considerable consistency in ratings among the different study investigators; relative to a reference rater, the other two study investigators had the same scoring in $95 \%$ and $91 \%$ of items. The most frequently documented elements were selfawareness (attained, 100\%; needing development, 100\%), professionalism (needing development, 100\%; attained, $99.0 \%$ ). The next most frequently documented elements were leadership: needing development $(49.0 \%)$, innova-

Table 1. Summary of Select Demographic Characteristics of the Study Population $(\mathrm{N}=104)$

\begin{tabular}{lc}
\hline Characteristics & No. (\%) \\
\hline Gender & \\
Male & $39(37.5)$ \\
Female & $65(62.5)$ \\
Race & \\
Asian & $67(64.4)$ \\
Caucasian & $18(17.3)$ \\
Hispanic & $7(6.7)$ \\
African American & $4(3.9)$ \\
Other & $8(7.7)$ \\
Education level & \\
Bachelor's degree & $104(100)$ \\
Master's degree & $10(9.6)$ \\
Age in years, Mean (SD) & $26.3(4.0)$ \\
\hline
\end{tabular}

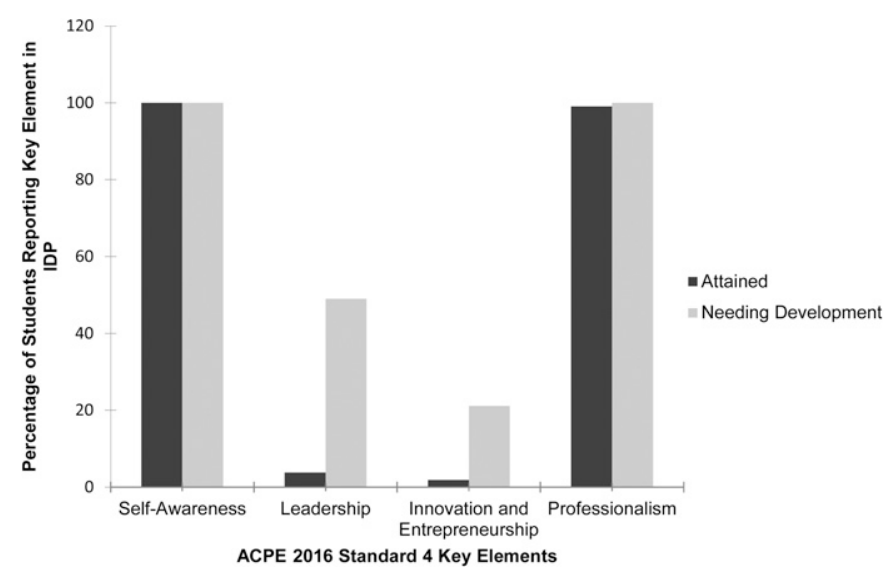

Figure 1. Summary of First-Year Doctor of Pharmacy Students Self-Reports. Percentage of students $(n=104)$ indicating some degree of attainment or needing development of each ACPE 2016 Standard 4 key element within their IDP.

tion and entrepreneurship: needing development (21.2\%). The last two elements, leadership: attained (3.9\%) and innovation and entrepreneurship: attained (1.9\%), were not as frequently reported. When the responses indicating attained or needing development were combined, selfawareness (100\%) and professionalism (100\%) were the most commonly documented key elements, followed by leadership (51.0\%) and innovation and entrepreneurship $(22.1 \%)$. A representative student quote demonstrating the key element of self-awareness was: "I am not entirely sure which direction I would like to pursue in pharmacy. My hope is that I can gain experience through different IPPE events and in my classes to help enhance my understanding." The key element of leadership can be seen in this quote regarding the student's 10-year goal: "Become a leader or mentor to the future generation of pharmacist." The key element of innovation and entrepreneurship may be viewed as the desire to own a business, but may also incorporate critical-thinking skills as seen in this student quote: "The quality of being able to adapt on the spot is a virtue. Acquire this quality by training to be a better critical thinker." The key element of professionalism is observed in this student quote: "Make an effort to not only learn what is required, but strive to learn more not only for yourself but ultimately for the patients."

Of the 10 academic advisors who were surveyed to gain insight on their perceptions of the use of the IDP, eight participated ( $80 \%$ response rate). The majority of advisors reported that the IDP aided in stimulating more productive and constructive meetings with the students $(87.5 \%, \mathrm{n}=7)$ and, overall, believed that the IDP was a beneficial tool for students' personal and professional development $(87.5 \%, \mathrm{n}=7)$. When asked if the advisors felt the IDP addressed the key elements of ACPE 2016 


\section{American Journal of Pharmaceutical Education 2019; 83 (6) Article 6825.}

Standard 4, all advisors reported that the IDP addressed self-awareness $(100 \% ; \mathrm{n}=8)$. The majority of advisors reported that the IDP addressed professionalism (87.5\%, $\mathrm{n}=7$ ), while fewer reported the IDP addressed leadership $(37.5 \%, \mathrm{n}=3)$ and innovation and entrepreneurship $(25.0 \%, \mathrm{n}=2)$. Some advisors also reported feeling that the IDP was a useful tool for their own continued personal and professional development $(75.0 \%, \mathrm{n}=6)$.

\section{DISCUSSION}

The objective of this study was to create and implement a planning tool that would aid pharmacy students in career planning, and to determine the extent to which the tool could also be used to facilitate tracking of pharmacy students' perceived progress on ACPE 2016, Standard 4, Personal and Professional Development. The IDP demonstrated the ability to track the four key elements of ACPE 2016, Standard 4 (self-awareness, leadership, innovation and entrepreneurship, and professionalism). Although certain key elements were reported more frequently than others, all four key elements of Standard 4 were capable of being tracked through the IDP, depending on the students' experiences and documentation. The ACPE 2016 Accreditation Standards define self-awareness as the ability to "examine and reflect on personal knowledge, skills, abilities, beliefs, biases, motivation, and emotions." All students who completed the IDP provided written responses that reflected personal introspection and self-assessment, and their reflections were further discussed with their faculty advisors during individual meetings.

Based on the data collected, the majority of new pharmacy students in this study documented awareness of the importance of possessing and developing selfawareness and professionalism while fewer students acknowledged the need for leadership and innovation/ entrepreneurship skills. Therefore; to fulfill the goals of ACPE Standard 4, further training and development is needed to ensure that an awareness of these latter skills is instilled in all PharmD students during their training. Because there are several existing curricular and cocurricular components available to address this (eg, legislative day activities in which all students advocate on behalf of the profession with their legislators, a student-run free clinic that provides services in an underserved community), we anticipate that as students progress through the PharmD program, they will demonstrate increased awareness and competencies in leadership and innovation/entrepreneurship.

We want to emphasize that the IDP is intended to complement existing programmatic elements and assessments that address personal and professional development. Pharmacy schools have implemented multiple mechanisms to promote the personal and professional growth of all students, including specialized courses and cocurricular activities to develop leadership, problem-solving, and professionalism. ${ }^{12-14,19}$ In addition, many programs have introduced pharmacy students to the use of self-assessment tools such as Myers Brigg, Strength Finders, the Grit Scale, the Birkman Method, and other tools to measure emotional intelligence. ${ }^{20-24}$ Addition of the IDP facilitates tracking of each student and aids in ensuring that the available programmatic offerings to promote personal and professional development are being synthesized and applied as intended.

In addition to addressing Standard 4, the IDP serves as a guide for pharmacy students to lead a discussion about self-evaluation, goals, and plans with their academic advisors. Responses from the faculty advisor surveys confirmed that the IDP helped facilitate collaborative meetings where the student and advisor could establish specific actions and plans to support the student in working towards their individual, professional goals.

At Touro University California, students are required to update their IDPs at least once a year and upload it into their $\mathrm{E}^{*}$ Value portfolio to help stimulate continued, productive discussions with their academic advisors. The information is also accessible to other faculty members and preceptors involved in the training of the students to further support their professional and career development. In addition to using the IDP as a professional development tool while in the PharmD program, the IDP has the potential to continue serving as a useful tool for professional and personal development even after graduation. The long-term utility of the IDP was supported by the positive responses on the faculty advisor survey, which indicated that the IDP is a useful tool for their own continued personal and professional development.

Although not the focus of this study, several elements of the CAPE Educational Outcomes 2013, Domain 3, Approach to Practice and Care, were also captured within the self-evaluation section of the IDP. ${ }^{11}$ CAPE, Domain 3.1, Problem Solving (Problem Solver), which is defined as the ability to "identify problems; explore and prioritize potential strategies; and design, implement, and evaluate a viable solution," is listed in the skills category of the IDP as "problem solving." CAPE, Domain 3.4, Interprofessional Collaboration (Collaborator), which is defined as the ability to "actively participate and engage as a health care team member by demonstrating mutual respect, understanding and values to meet patient care needs," is captured in the IDP skills category as "collaboration and teamwork." CAPE, Domain 3.6, Communication 


\section{American Journal of Pharmaceutical Education 2019; 83 (6) Article 6825.}

(Communicator), which is defined as the ability to "effectively communicate verbally and nonverbally when interacting with an individual, group or organization," is captured in the following three skills listed in the IDP skills category: oral communication, written communication, and interpersonal communication.

There are several limitations of this study. One limitation involves the self-reported data within the IDPs. There may be inaccuracies or missing elements in the data that are reflective of the students' own interpretation. However, this potential limitation can be overcome through student discussions with their advisors, along with experiences and feedback obtained as the students progress through the program. We expect that in future self-reflections, students will be able to identify and correct their early misperceptions as they gain experience and successes. If misperceptions persist in critical areas, they will likely become apparent over time as program grades and assessments diverge from student expectations and self-evaluations. As such, the information in the IDPs could provide insight that poor self-reflection and/or inaccurate self-evaluation may be a root cause for some students' difficulty with progressing in the program. If this is the case, learning strategies that address these deficits could be shared with the student in an effort to improve future performance.

Another limitation of the data presented is the timeframe of the data collection. The IDP data were collected within the first two months of the students beginning pharmacy school. Key elements that were described by a smaller percentage of students, such as leadership and innovation/ entrepreneurship, are meant for the students to develop further as they progress throughout the PharmD program. Attaining leadership positions in professional organizations, for example, was not possible for the first-year students within that timeframe. Thus, the data provide a snapshot of where the students were at the beginning of the program. Our findings also emphasize the importance of providing targeted development of leadership and innovation/entrepreneurship skills during their PharmD training as many of the entering students appeared to be less aware of the importance of and need to develop these skills compared to self-awareness and professionalism.

A final potential limitation identified is the wording of the skills listed in the self-evaluation section of the IDPs. If the self-evaluation skills and prompts had been modified to more directly address leadership and innovation/entrepreneurship, students may have reported these elements more frequently. However, specific prompts for self-awareness and professionalism were not used and the students still addressed these elements. Therefore, further refinement of the IDP to better highlight key elements is being considered to help emphasize their importance to the practice of pharmacy. This may take the form of adding ACPE definitions and guidelines of the key elements during orientation and further training of the students and advisors in the use of the IDP, and/or their inclusion on the template for the actual IDP form.

At Touro University California, the IDP will continue to be introduced to incoming pharmacy students and regularly updated throughout the PharmD program. Thus, potential limitations of the IDP, identified above, will be reassessed longitudinally to determine if other interventions such as advisor and program feedback compensate and self-correct for these weaknesses over time. In addition, longitudinal academic advisor development sessions will be implemented. To supplement their initial training, future sessions will educate faculty advisors in more detail about the IDP function and purpose. Advisors will be trained more rigorously on implementation strategies and interventions to help students improve weaknesses, formulate career goals, and develop an action plan to achieve stated goals. Prompts to remind faculty advisors to encourage their students to develop leadership and innovation/entrepreneurship, in addition to self-awareness and professionalism, will be incorporated. Some basic science faculty members also expressed the need for better education about pharmacy careers and professional development opportunities to properly support their advisees. Finally, opportunities for expanded use of the IDPs with postgraduate trainees (residents and fellows), university faculty members, and pharmacy preceptors will be explored. The NIH has recognized the value of implementing IDPs into biomedical graduate education and this tool also appears to have similar potential for impacting pharmacy education and training.

\section{CONCLUSION}

The IDP is a career development tool that can help address ACPE 2016, Standard 4, Personal and Professional Development. This structured mechanism helps pharmacy students self-evaluate their skills, define career goals, and develop individualized implementation plans that will allow them to achieve their stated goals. By completing and updating their IDPs, pharmacy students can address Standard 4 key elements (self-awareness, leadership, innovation and entrepreneurship, and professionalism), and the program can support and track the individual progress of each student in developing these essential characteristics.

\section{ACKNOWLEDGMENTS}

We appreciate the critical feedback and suggestions provided by Drs. Shadi Doroudgar, John Inciardi, Neil 


\section{American Journal of Pharmaceutical Education 2019; 83 (6) Article 6825.}

Willits, Mohamed Jalloh, and Tara Jenkins. We also appreciate the assistance of Mrs. Charity Yamada for deidentifying the IDP forms for analyses.

\section{REFERENCES}

1. Individual Development Plan - Stanford Biosciences PhD Programs. http://biosciences.stanford.edu/current/idp/. Accessed September 2, 2016.

2. Professional Development: Individual Development Plan (IDP). https://gradstudies.ucdavis.edu/professional-development/ individual-development-plan-idp. Accessed September 2, 2016.

3. Berkeley Graduate Division: Individual Development Planning (IDP). http://grad.berkeley.edu/idp/. Accessed September 2, 2016.

4. BPH Individual Development Plan (IDP) PhD Program in Biological Sciences in Public Health. https://www.hsph.harvard.edu/ biological-sciences/bph-individual-development-plan-idp/. Accessed December 17, 2017.

5. The Individual Development Plan for Graduate Students at Rutgers University. http://rwjms.rutgers.edu/gsbs/student_affairs/ documents/IDPRutgers.pdf. Accessed December 17, 2017.

6. Hobin JA, Fuhrmann CN, Lindstaedt B, Clifford PS. You need a game plan. Science. https://www.sciencemag.org/careers/2012/09/

you-need-game-plan and http://myidp.sciencecareers.org/. Accessed December 17, 2017.

7. Individual Development Plan for Postdoctoral Fellows. Federation of American Societies for Experimental Biology (2012). http:// www.faseb.org/portals/0/pdfs/opa/idp.pdf. Accessed December 17, 2017.

8. NIH Encourages Institutions to Develop Individual Development Plans for Graduate Students and Postdoctoral Researchers. July 23, 2013. http:/grants.nih.gov/grants/guide/notice-files/NOT-OD-13-093. html. Accessed September 2, 2016.

9. Accreditation Council for Pharmacy Education. Accreditation standards and key elements for the professional program in pharmacy leading to the Doctor of Pharmacy degree ("Standards 2016"). https:// www.acpe-accredit.org/pdf/Standards2016FINAL.pdf. Published February 2, 2015. Accessed September 2, 2016. 10. Accreditation Council for Pharmacy Education. Guidance for the accreditation standards and key elements for the professional program in pharmacy leading to the Doctor of Pharmacy degree ("Guidance for Standards 2016",) https://www.acpe-accredit.org/pdf/ GuidanceforStandards2016FINAL.pdf. Published February 2, 2015. Accessed September 2, 2016.
11. Center for the Advancement of Pharmaceutical Education. Educational Outcomes, 2013. http://www.aacp.org/documents/ CAPEoutcomes071213.pdf. Accessed December 16, 2016.

12. Feller TT, Doucette WR, Witry MJ. Assessing opportunities for student pharmacist leadership development at schools of pharmacy in the United States. Am J Pharm Educ. 2016;80(5): Article 79.

13. Ramia E, Salameh P, Btaiche IF, Saad AH. Mapping and assessment of personal and professional development skills in a pharmacy curriculum. BMC Med Ed. 2016;16:19.

14. Ross LA, Janke KK, Boyle CJ. Preparation of faculty members and students to be citizen leaders and pharmacy advocates. Am J Pharm Educ. 2013;77(10):Article 220.

15. Gholke AL, Ray DB, El-Ibiary SY, Barletta JF. Characteristics of the ideal postgraduate year 1 pharmacy practice residency candidate: a survey of residency program directors. $J$ Pharm Pract. 2014;27(1):84-88.

16. Horner KE. The good pharmacist: characteristics, virtues, and habits. Am J Health Syst Pharm. 2012; 69(23):2102-2104.

17. Jellinek-Cohen SP, Cohen V, Bucher KL, et al. Factors used by pharmacy residency programs to select residents. Am J Health Syst Pharm. 2012;69:1105-1106.

18. Thompson DC, Nuffer W, Brown K. Characteristics valued by the pharmacy practice community when hiring a recently graduated pharmacist. Am J Pharm Educ. 2012;76(9):Article 170.

19. Martin LC, Donohoe KL, Holdford DA. Decision-making and problem-solving approaches in pharmacy education. Am J Pharm Educ. 2016;80(3):Article 52.

20. Janke KK, Farris KB, Kelley KA. StrengthsFinder signature themes of talent in doctor of pharmacy students in five Midwestern pharmacy schools. Am J Pharm Educ. 2015;79(4):Article 49.

21. Lawrence L. Applying transactional analysis and personality assessment to improve patient counseling and communication skills. Am J Pharm Educ. 2007;71(4):Article 817.

22. Maxwell WD, Grant AD, Fabel PH. Impact of the Birkman Method assessment on pharmacy student self-confidence, selfperceptions, and self-awareness. Am J Pharm Educ.

2016;80(9):Article 148.

23. Nelson MH, Fierke KK, Sucher BJ, Janke KK. Including emotional intelligence in pharmacy curricula to help achieve CAPE outcomes. Am J Pharm Educ. 2015;79(4):Article 48.

24. Palisoc AJL, Matsumoto RR, Ho J, Perry PJ, Tang TT, Ip EJ. Relationship between grit with academic performance and attainment of postgraduate training in pharmacy students. Am J Pharm Educ. 2017;81(4):Article 67. 
American Journal of Pharmaceutical Education 2019; 83 (6) Article 6825.

Appendix 1. Individual Development Plan (IDP) Template

Touro University California

Name:

Date:

\section{Professional Goals}

My professional goals and career aspirations (in the next year, 5 years, 10, years):

1 year:

5 years:

10 years:

Talents and skills needed to achieve these aspirations:

(If long-term goals are unknown, what information do you need to set these goals?)

Skills

\section{Self-Evaluation}

Oral communication

Talents/Strengths

Weaknesses

Written communication

Technical skills

Time management and organization

Problem solving

(also consider creativity, initiative)

Decision making

(also consider risk taking, CQI)

Collaboration and teamwork

Work ethic

(also consider motivation and discipline) Other:

\section{Action Plan}

Opportunities available to improve in targeted areas and actions needed to achieve goals (including timeline): 


\section{American Journal of Pharmaceutical Education 2019; 83 (6) Article 6825.}

Appendix 2. Survey for Faculty Advisors Regarding Perceptions of IDP. Yes-or-no responses were collected for each question.

Do you feel that the Individual Development Plan (IDP) that students are required to complete aid in stimulating more productive and constructive meetings?

Overall, do you feel the IDP tool is beneficial for the students' personal and professional development?

Do you feel the IDP addresses ACPE 2016 Standard 4 Key element Self Awareness?

Do you feel the IDP addresses ACPE 2016 Standard 4 Key element Leadership?

Do you feel the IDP addresses ACPE 2016 Standard 4 Key element Innovation and Entrepreneurship?

Do you feel the IDP addresses ACPE 2016 Standard 4 Key element Professionalism?

Do you feel a need to be better educated about pharmacy careers and professional development opportunities to better support your advisees?

Do you feel that the IDP is a useful tool for your own continued personal and professional development? 